\title{
Purification and Some Properties of Chitin-binding Hemagglutinin from Conidiobolus lamprauges
}

\author{
Fumiyasu IsHIKawa, Kunio OIsHi and Kô AIDA \\ Institute of Applied Microbiology, The University of Tokyo, Tokyo 113, Japan \\ Received June 17, 1980
}

\begin{abstract}
A chitin-binding hemagglutinin was purified about 50 -fold from the culture filtrate of Conidiobolus lamprauges. Hemolytic factor(s) and $\beta$ - $N$-acetylglucosaminidase coexisting with the hemagglutinin were removed by treating the culture filtrate with CM Sephadex and formalinized human erythrocytes.

Purified hemagglutinin formed large aggregates upon ultrafiltration. The hemagglutinin had a major and a minor band in sodium dodecyl sulfate polyacrylamide gel electrophoresis. The major band of this hemagglutinin was a protein containing a small amount of sugar, and its molecular weight was approximately 86,000 .

The hemagglutinin was strongly inhibited by $N$-acetyl chitobi, tri and tetraose; moderately inhibited by phenyl and $p$-nitrophenyl $\beta$ - $N$-acetyl-D-glucosaminides; and weakly inhibited by Dglucosamine and $N$-acetyl-D-glucosamine. $\beta$-Configuration was required for inhibition.
\end{abstract}

A number of carbohydrate-binding proteins or hemagglutinins have been found and purified. ${ }^{1,2)} \quad N$-Acetyl-D-glucosamine-binding hemagglutinins have been obtained from plants $^{2)}$ and one of them, wheat germ agglutinin, was given special attention because of the agglutination of various animal cells, in particular, malignant cells and protease-treated normal cells, ${ }^{3 \sim \tilde{)})}$ the binding to chitin ${ }^{6)}$ and to bacterial cell wall polymers, ${ }^{7)}$ and the inhibition of fungal growth. ${ }^{8)}$

In the course of studies on microbial hemagglutinins, ${ }^{9 \sim 13\rangle}$ we have found that Conidiobolus lamprauges produces a chitin-binding hemagglutinin. This organism belongs to the order Entomophthorales, which is known to include strains causing diseases in insects and mites. The production of hemagglutinin was speciesspecific. $^{14)}$

Investigation of this hemagglutinin was expected to clarify its physiological role in $C$. lamprauges in natural field. Unlike the cases of plant $N$-acetyl-D-glucosamine-binding hemagglutinins, ${ }^{2)}$ however, purification of the hemagglutinin was very difficult and did not succeed by various conventional methods for protein purification.

This paper describes the purification of $C$. lamprauges agglutinin by an affinity adsorption using formalinized human erythrocytes as the ligand-matrix. It also describes the sugar specificity and other properties of purified hemagglutinin.

\section{MATERIALS AND METHODS}

Chemicals. Oligosaccharides of $N$-acetyl-D-glucosamine were prepared from chitin powder by the method of Raply. ${ }^{15}$ ) All other sugars were of the purest grade and purchased from Nakarai Chemicals Ltd., Kyoto.

Microorganism. C. lamprauges No. 454 was cultured as described previously. ${ }^{14}$ )

Purification of C. lamprauges hemagglutinin. To 2.5 liters of culture filtrate was added $1.3 \mathrm{~kg}$ of solid ammonium sulfate, and the mixture was left to stand at $4^{\circ} \mathrm{C}$ overnight. The precipitate formed was collected by centrifugation, dissolved in $0.05 \mathrm{M}$ phosphate buffer $(\mathrm{pH} 6.0)$ and dialyzed extensively against the same buffer at $4^{\circ} \mathrm{C}$. The dialyzed fraction was applied to a $2.5 \times 16 \mathrm{~cm}$ column of CM Sephadex C-50 (Pharmacia Fine Chemicals AB, Uppsala) equilibrated with the above phosphate buffer. The column was washed with the same buffer until the eluate showed an optical density of less than 0.05 at a wave length of $280 \mathrm{~nm}$, and then developed with a linear gradient from $0.05 \mathrm{M}$ to $0.5 \mathrm{~m}$ phosphate buffer $(\mathrm{pH} 6.0)$. Fractions which had hemagglutinating activity were collected and dia- 
lyzed against $0.05 \mathrm{M}$ phosphate buffered saline ( $\mathrm{pH} 7.0$ ). Affinity adsorption of $C$. lamprauges agglutinin onto formalinized human type 0 erythrocytes (FE), which were prepared as described by Butler, ${ }^{16)}$ was performed according to the method of Reitherman et al. ${ }^{17)}$ with slight modification. Fifty milliliters of the active fraction and $10 \mathrm{ml}$ (packed volume) of $\mathrm{FE}$ were combined, and then the mixture was stirred at $4^{\circ} \mathrm{C}$ for an hour with gentle shaking. The cells were washed five times at $4^{\circ} \mathrm{C}$ with 100 cell volumes of saline by centrifugation at $3,000 \times g$ for $5 \mathrm{~min}$. The washed cells were suspended in $15 \mathrm{ml}$ of saline containing $0.3 \mathrm{M} \mathrm{N}$-acetyl-D-glucosamine, and incubated at $4^{\circ} \mathrm{C}$ for an hour with shaking. The supernatant was collected by centrifugation at $5,000 \times g$ for $5 \mathrm{~min}$ and recentrifuged at $10,000 \times g$ for $30 \mathrm{~min}$, passed through a Millipore Filter (pore size $0.45 \mu \mathrm{m}$, Millipore Filter Corp., Massachusetts) to remove the cells and breakages completely, and dialyzed exhausively against $0.05 \mathrm{~m}$ phosphate buffer to remove sugar. Samples for chemical analyses were concentrated with Toyo Ultrafilter UK-50 (Toyo Roshi Co. Ltd., Tokyo).

Electrophoresis. Polyacrylamide gel electrophoresis was carried out at $\mathrm{pH} 4.3$ and 8.9 according to Reisfeld et $a .^{(8)}$ and Davis, ${ }^{19)}$ respectively. Polyacrylamide gel electrophoresis in the presence of sodium dodecyl sulfate (SDS) and 2-mercaptoethanol was performed at pH 7.2 by the method of Weber and Osbern, ${ }^{20)}$ in which samples were boiled with $1 \% \operatorname{SDS}$ and 2-mercaptoethanol for $5 \mathrm{~min}$ before application to the gels.

Determination of hemagglutinating and $\beta$-N-acetyl- glucosaminidase activities. Assays of hemagglutinating activity, hemagglutination inhibition by sugars, and $\beta-N$-acetylglucosaminidase activity were performed as described previously. ${ }^{14}$ )

Determination of protein content. Protein content was quantitated by spectrophotometric method using Coomassie Brilliant Blue G-250 (Sigma Chemical Co., St. Louis, Mo). ${ }^{21}$

Determination of molecular weight of hemagglutinin. Molecular weight was estimated by comparison of the mobility of samples with those of commercial markers (BDH Molecular Weight Marker, BDH Chemicals Ltd., England) on SDS electrophoresis. Proteins and sugars on the gels were stained with Coomassie Brilliant Blue $\mathrm{R}-250$ (Sigma) and by periodic acid-Schiff reagent, ${ }^{22)}$ respectively.

\section{RESULTS}

Purification of the chitin-binding hemagglutinin from $C$. lamprauges was performed in three steps: ammonium sulfate precipitation of the culture filtrate, chromatography on $\mathrm{CM}$ Sephadex, and affinity adsorption to FE. Almost all the hemagglutinating activity in the filtrate was recovered by ammonium sulfate precipitation. The agglutinin was adsorbed on CM Sephadex in the presence of $0.05 \mathrm{M}$ phosphate buffer and eluted at $0.3 \mathrm{~m}$ phosphate

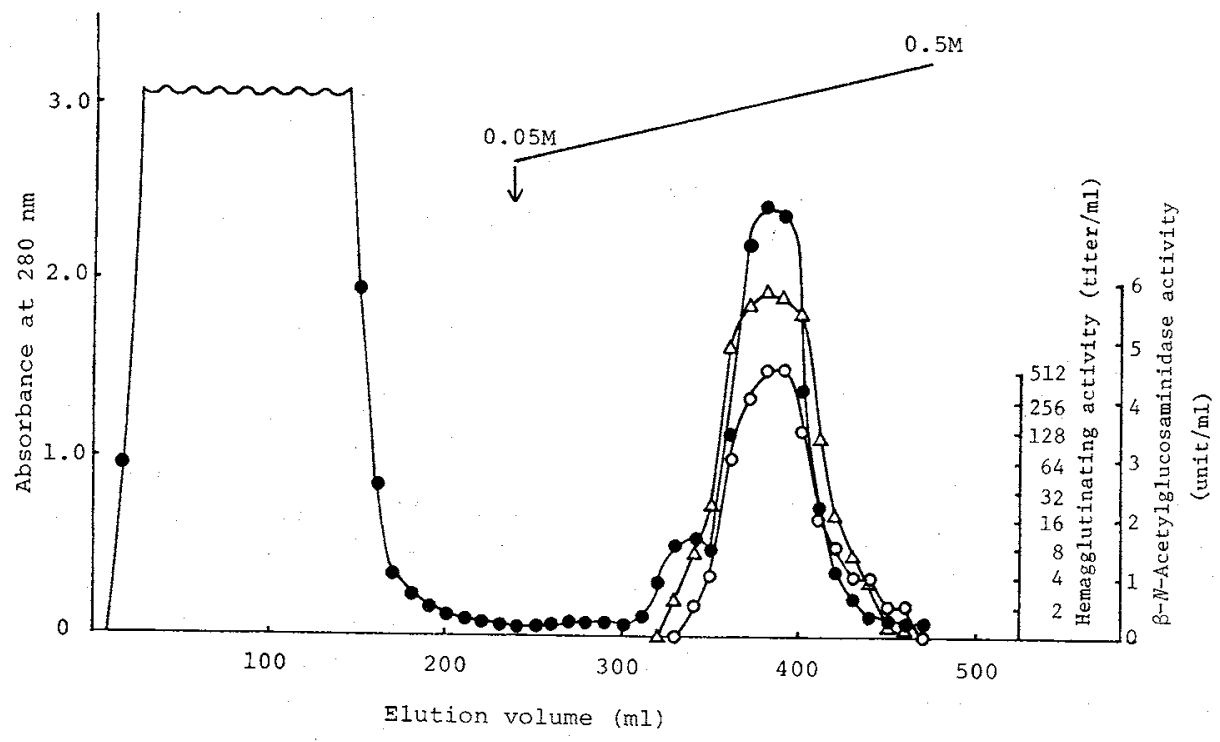

FIG. 1. Ion Exchange Chromatography of Ammonium Sulfate Fraction on CM Sephadex C-50.

Arrow indicates the opening of a linear gradient from $0.05 \mathrm{M}$ to $0.5 \mathrm{M}$ phosphate buffer. ance at $280 \mathrm{~nm} ; O$, hemagglutinating activity; $\triangle, \beta-N$-acetylglucosaminidase activity. 
Table I. Retentivity of Formalinized

ERYTHROCYTES TO Conidiobolus lamprauges

AGGLUTININ AND $\beta$ - $N$-ACETYLGLUCOSAMINIDASE

\begin{tabular}{|c|c|c|}
\hline & \multicolumn{2}{|c|}{ Retentive activity } \\
\hline & $\mathrm{CLA}^{a}$ & $\beta$-GlcNAcase ${ }^{b}$ \\
\hline CM Sephadex fraction & 100 & 100 \\
\hline FE adsorbed ${ }^{\circ}$ & 86.8 & 2.1 \\
\hline FE washing-I & 74.5 & 0.8 \\
\hline II & 74.5 & 0 \\
\hline III & 74.5 & 0 \\
\hline IV & 74.5 & 0 \\
\hline $\mathrm{V}$ & 74.5 & 0 \\
\hline
\end{tabular}

a Conidiobolus lamprauges agglutinin.

$b \quad \beta$-N-Acetylglucosaminidase.

- Activity in CM Sephadex fraction minus activity in supernatant of FE treatment. Conditions are shown in MATERIALS AND METHODS.

buffer with a linear gradient. Although this process could not separate the agglutinin from coexisting $\beta-N$-acetylglucosaminidase (Fig. 1), it removed unknown hemolytic factor(s) present in the culture filtrate and ammonium sulfate precipitate. The agglutinin in $\mathrm{CM}$ Sephadex eluates was efficiently adsorbed onto FE and eluted with $0.3 \mathrm{M}$ of $\mathrm{N}$-acetyl-Dglucosamine, resulting in a 50 -fold purification with $14 \%$ recovery. On the other hand, most $\beta$ - $N$-acetylglucosaminidase was not adsorbed to $\mathrm{FE}$ and remained in the supernatant fluid. The enzyme activity was scarcely detected in the washing of FE after hemagglutinin adsorption (Table I). The results of the purification are summarized in Table II.

SDS polyacrylamide gel electrophoresis of the hemagglutinin preparation obtained by FE treatment showed a major and a minor band by staining with Coomassie Brilliant Blue (Fig. $2 a)$. By the periodic acid-Schiff reagent pro-

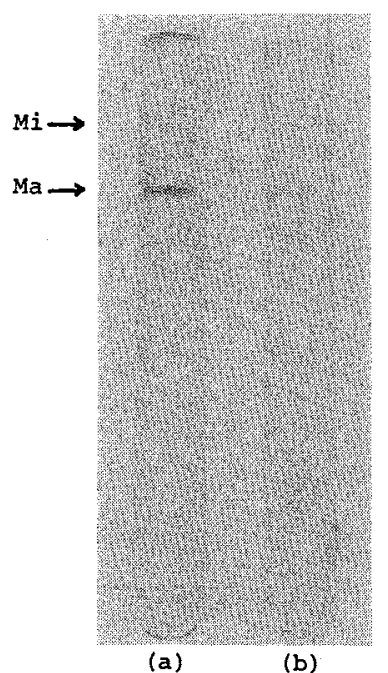

FrG. 2. Polyacrylamide Gel Electrophoresis with Sodium Dodecyl Sulfate.

(a) and (b) were respectively stained with Coomassie Brilliant Blue and periodic acid-Schiff reagent. Ma and $\mathrm{Mi}$ indicate the major and the minor band, respectively.

cedure, only the major band was stained (Fig. 2b). The major and the minor component had molecular weight values of ca. 86,000 and 143,000 , respectively, by SDS electrophoresis using $10 \%$ gel concentration. These values, however, varied from 86,000 to 110,000 and from 143,000 to 225,000 , respectively, when the gel concentration was changed (Fig. 3). In plotting these values to gel concentration, these molecular weights of both components approached asymptotically $c a .86,000$ and 143,000 (Fig. 4). When the hemagglutinin preparation was electrophoresed on $3 \%$ polyacrylamide gel without SDS at $\mathrm{pH} 4.3$ or 8.9 , no band of proteins was detected in the running gel, indicating that the agglutinin concentrated

Table II. Purification of Conidiobolus lamprauges Agglutinin

\begin{tabular}{|c|c|c|c|c|c|c|c|c|c|}
\hline Fractions & $\begin{array}{l}\text { Volume } \\
\text { (ml) }\end{array}$ & $\begin{array}{l}\text { Protein } \\
(\mathrm{mg})\end{array}$ & $\underset{\text { (titer) }}{\mathrm{HAU}^{a}}$ & $\begin{array}{c}\text { HA } \\
\text { specific } \\
\text { activity }\end{array}$ & $\begin{array}{c}\text { HA } \\
\text { recovery } \\
(\%)\end{array}$ & $\underset{\text { (unit) }}{\mathrm{EU}^{b}}$ & $\begin{array}{l}\text { Enzyme } \\
\text { specific } \\
\text { activity }\end{array}$ & $\begin{array}{c}\text { Enzyme } \\
\text { recovery } \\
(\%)\end{array}$ & $\begin{array}{c}\text { HA/ } \\
\text { Enzyme }\end{array}$ \\
\hline Culture filtrate & 2600 & 410 & 20800 & 50.7 & 100 & 572 & 1.40 & 100 & 36 \\
\hline$\left(\mathrm{NH}_{4}\right)_{2} \mathrm{SO}_{4}$ fraction & 147 & 163 & 18816 & 115 & 90 & 404 & 4.48 & 70 & 46 \\
\hline CM fraction & 50 & 62.6 & 12800 & 204 & 62 & 250 & 3.99 & 43 & 51 \\
\hline FE fraction & 30 & 1.9 & 2880 & 2618 & 14 & 3.6 & 1.89 & 0.6 & 1385 \\
\hline
\end{tabular}

a Hemagglutinating activity, units.

$\delta \beta$ - $N$-Acetylglucosaminidase activity, units. 

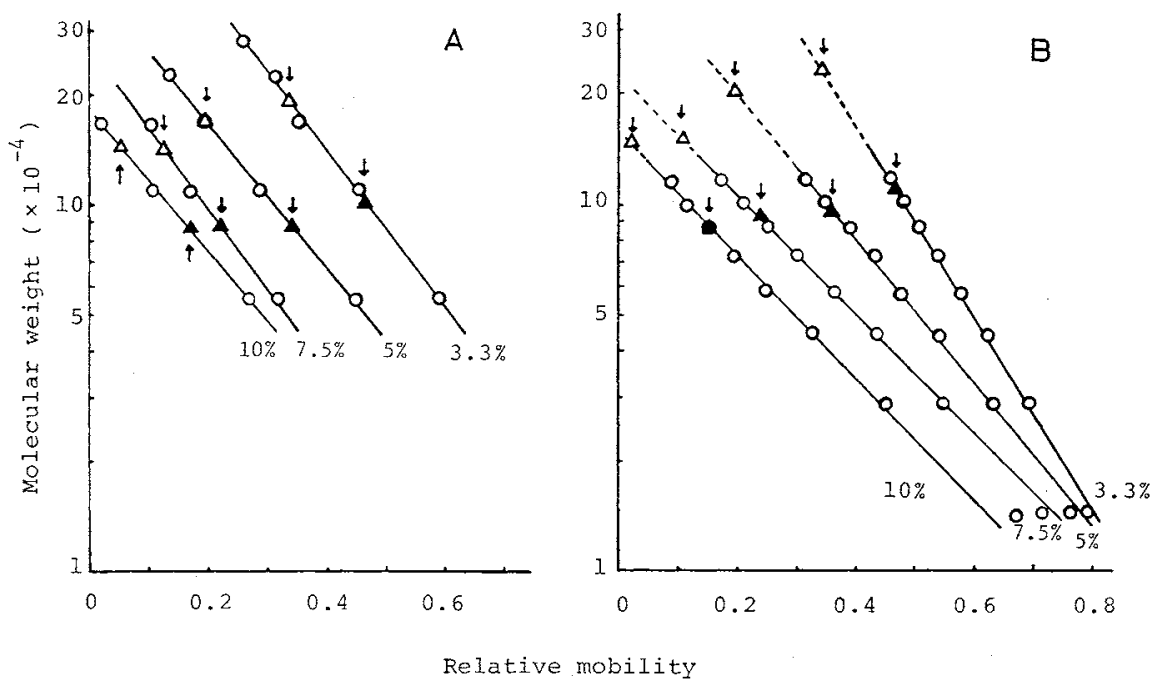

FIG. 3. Log Molecular Weight vs. Relative Mobility in SDS Gel Electrophoresis of Molecular Weight Markers (O) [BDH Marker No. 44230 2R (A) and No. 44223 2U (B)].

The major $(\Delta)$ and minor $(\Delta)$ components are shown.

in the sample gel formed large aggregates. This is the case when the agglutinin preparation obtained by FE treatment was concentrated by ultrafiltration; visible aggregates were observed.

Sugar specificity of the purified hemagglutinin preparation was investigated by hemagglutination inhibition tests using $N$-acetyl-Dglucosamine and related compounds (Table III) Among the series of oligo $N$-acetyl-D-glucosaminides examined, $N, N^{\prime}, N^{\prime \prime}, N^{\prime \prime \prime}$-tetraacetylchitotetraose showed the most powerful inhibition. $N, N^{\prime}, N^{\prime \prime}$-Triacetylchitotriose was also showed marked inhibitory activity. Inhibition by $N$-acetyl-D-glucosamine was rather weak and almost the same as those by D-glucosamine and D-mannosamine. $p$-Nitrophenyl- $\beta$ - and phenyl- $\beta$ - $N$-acetyl-D-glucosaminides were as inhibitory as $N, N^{\prime}$-diacetylchitobiose, while their $\alpha$-anomers were not inhibitory. Cellobiose which was as inhibitory as $N, N^{\prime}$ diacetylchitobiose to Cytisus type lectins ${ }^{23,24\}}$ was not inhibitory. Among polysaccharides examined (Table IV), ethylene glycol chitin, a soluble derivative of poly $\mathrm{N}$-acetyl-D-glucosamine, ${ }^{25)}$ and a glycoprotein preparation from gastric mucus of bullfrog were inhibitory to

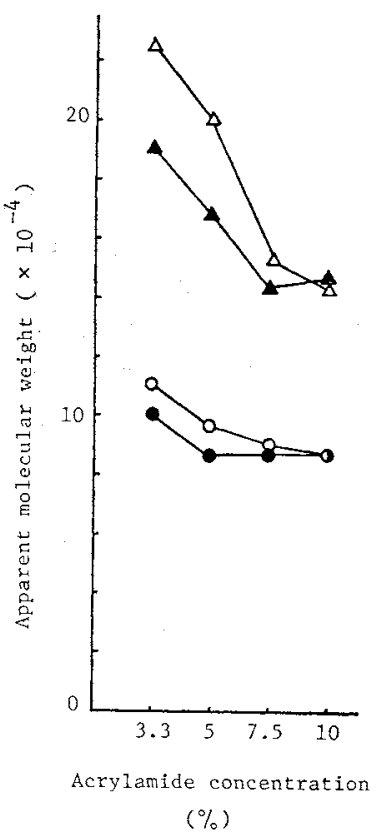

FIG. 4. Apparent Molecular Weights of Two Components on SDS Gel Electrophoresis vs. Acrylamide Gel Concentration.

(-) and (O) show the molecular weights of the major component calculated by using BDH Marker No. $442302 \mathrm{R}$ and No. 44223 2U, respectively. (A) and $(\triangle)$ show those of the minor component calculated by using No. $442302 \mathrm{R}$ and No. 44223 2U, respectively. 
TABLE III. InHIBITION of Conidiobolus lamprauges AGgLutinin BY MONO-, Oligo*, AND Amino SUgARS

\begin{tabular}{|c|c|c|}
\hline Sugars & & $\begin{array}{l}\text { Minimum concentration (mM) } \\
\text { for complete inhibition of } 4 \\
\text { hemagglutinating doses }\end{array}$ \\
\hline \multirow[t]{3}{*}{ Neutral sugars } & $\begin{array}{l}\text { D-Ribose, D-arabinose, L-arabinose, } \\
\text { D-xylose }\end{array}$ & $>200$ \\
\hline & $\begin{array}{l}\text { D-Glucose, D-mannose, D-galactose, } \\
\text { D-fructose, L-sorbose, D-fucose, L-fucose, } \\
\text { L-rhamnose, D-mannitol, 2-deoxy-D-glucose }\end{array}$ & $>167$ \\
\hline & Sucrose, lactose, maltose, cellobiose, raffinose & $>60$ \\
\hline \multirow[t]{14}{*}{ Amino sugars } & D-Glucosamine & 28 \\
\hline & $N$-Acetyl-D-glucosamine & 28 \\
\hline & D-Mannosamine & 28 \\
\hline & $N$-Acetyl-D-mannosamine & $>68$ \\
\hline & D-Galactosamine & $>84$ \\
\hline & $N$-Acetyl-D-galactosamine & $>68$ \\
\hline & $N, N^{\prime}$-Diacetylchitobiose & 0.73 \\
\hline & $N, N^{\prime}, N^{\prime \prime}$-Triacetylchitotriose & 0.25 \\
\hline & $N, N^{\prime}, N^{\prime \prime}, N^{\prime \prime \prime}-$ Tetraacetylchitotetraose & 0.19 \\
\hline & $p$-Nitrophenyl- $\alpha-N$-acetyl-D-glucosaminide & $>21.6$ \\
\hline & $p$-Nitrophenyl- $\beta$ - $N$-acetyl-D-glucosaminide & 0.61 \\
\hline & Phenyl- $\alpha-N$-acetyl-D-glucosaminide & $>26.9$ \\
\hline & Phenyl- $\beta$ - $N$-acetyl-D-glucosaminide & 1.0 \\
\hline & $p$-Aminobenzyl-1-thio- $\beta$ - $N$-acetyl-D-glucosaminide & 32 \\
\hline
\end{tabular}

TABLE IV. INHIBITION OF Conidiobolus lamprauges AGGLUTININ By POLYSaCCHARIDES

\begin{tabular}{lc}
\hline \multicolumn{1}{c}{ Polysaccharides } & $\begin{array}{c}\text { Minimum concentration } \\
\text { (\%) for complete } \\
\text { inhibition of } 4 \\
\text { hemagglutinating } \\
\text { doses }\end{array}$ \\
\hline $\begin{array}{l}\text { Ethylene glycol chitin } \\
\text { Gastric mucus of bullfrog } \\
(\mathrm{B}+\mathrm{H})\end{array}$ & 0.0025 \\
Ovomucoid & 0.032 \\
$\quad$ (Trypsin inhibitor $)$ & $>1.3$ \\
Heparin & $>2.0$ \\
Hyarulonic acid & $>6.0$ \\
Gum arabic & $>4.0$ \\
Dextrin & $>0.13$ \\
$\kappa$-Carrageenan & $>0.13$ \\
Tamarind seed & $>0.13$ \\
Xylan & $>0.13$ \\
Karaya gum & $>0.13$ \\
Guar gum & $>0.13$ \\
Locast bean gum & $>0.13$ \\
Tragacanth gum & \\
\hline
\end{tabular}

the present agglutinin, while ovomucoid (Trypsin inhibitor, Type II-0, Sigma) which is a glycopeptide containing a lot of $N$-acetyl-D- glucosamine ${ }^{28)}$ was no more inhibitory than other polysaccharides.

Effects of $\mathrm{pH}$ and temperature on the activities of the hemagglutinin and the coexisting $\beta$ $N$-acetylglucosaminidase are showed in Figs. 5 and 6. Hemagglutinating activity scarcely varied in the range of $\mathrm{pH} 5.0$ to 8.9 and $4^{\circ} \mathrm{C}$ to $42^{\circ} \mathrm{C}$. On the other hand, the enzyme activity reached a maximum at $\mathrm{pH} 5.0$ and at $45^{\circ} \mathrm{C}$ to $55^{\circ} \mathrm{C}$.

\section{DISCUSSION}

In the genus Conidiobolus, C. lamprauges was the sole species which showed human erythrocyte-agglutinating activity. The activity was always accompanied with $\beta$ - $N$-acetylglucosaminidase activity. ${ }^{14)}$ Conventional procedures for protein purification such as gel filtration with Sephadex, ion exchange chromatographies using DEAE and CM Sephadexes, and adsorption chromatography using hydroxyapatite could not separate the agglutinin from the enzyme activity, and the possibility that the enzyme activity was given by a bi- 


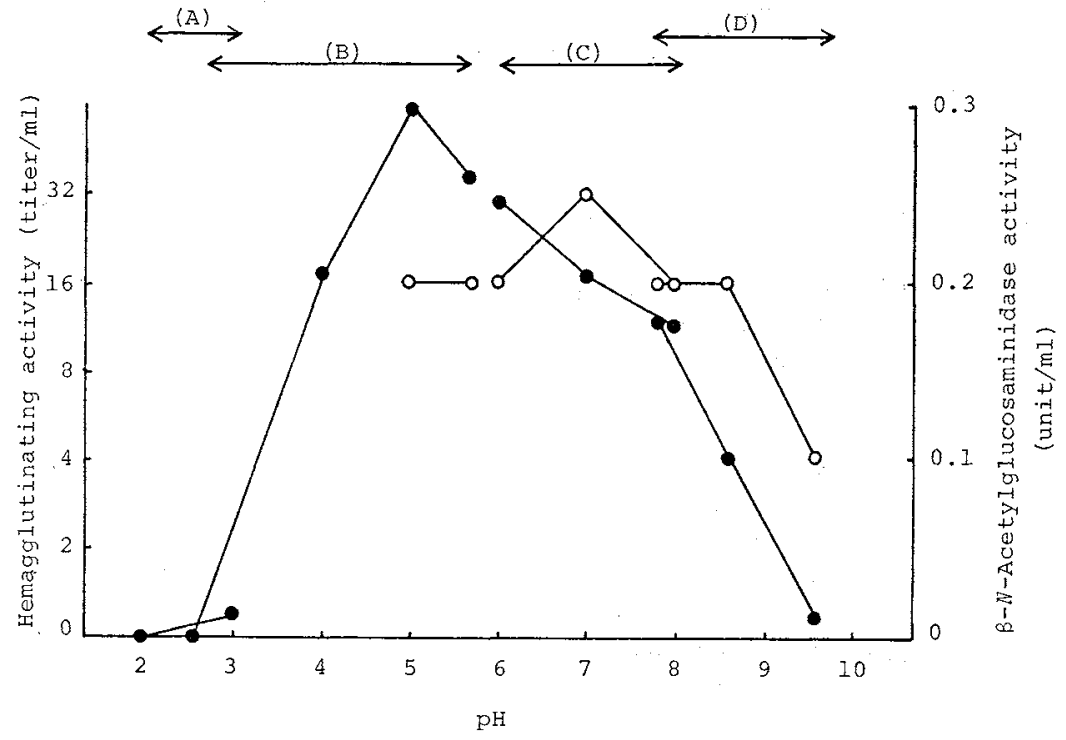

FIG. 5. Optimum $\mathrm{pH}$ of Hemagglutinin and $\beta-N$-Acetylglucosaminidase Activities.

Buffer system of ion strength 0.1: A, glycine-hydrochloride; B, citrate; C, phosphate; D, Trishydrochloride. O, Hemagglutinin; $\bullet, \beta$ - $N$-acetylglucosaminidase.

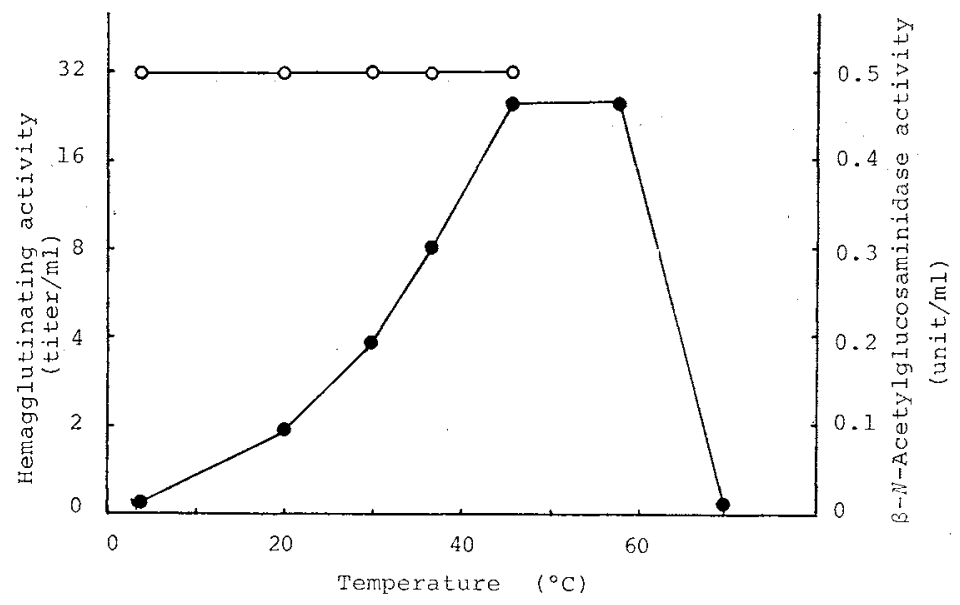

FIg. 6. Optimum Temperature of Hemagglutinin and $\beta$ - $N$-Acetylglucosaminidase Activities.

O, Hemagglutinin; $\bullet, \beta$ - $N$-acetylglucosaminidase.

functional hemagglutinin remains to be elucidated.

FE have been employed as an affinity adsorbent for separation of hemagglutinins, which was not separable from coexisting materials by conventional techniques. ${ }^{17,27,28)}$ By using an FE adsorption method, we could now separate C. lamprauges agglutinin from $\beta-N$ acetylglucosaminidase. FE, however, were not stable in the culture filtrate and its ammonium sulfate precipitate of $C$. lamprauges. Therefore, CM Sephadex treatment prior to FE treatment was employed for removal of the hemolytic factor(s) in the filtrate. CM Sephadex could adsorb the hemagglutinin, the enzyme, and the hemolytic factor(s). Phosphate buffer $0.3 \mathrm{M}$ eluted the first two, but not the latter. Separation of the agglutinin from 
Table V. Relative Affinity of Amino Sugars to Conidiobolus lamprauges Agglutinin AND $N$-ACETYL-D-GLUCOSAMINE-BINDING LECTINS

\begin{tabular}{|c|c|c|c|c|c|}
\hline Sugars & $\mathrm{CLA}^{a}$ & $\mathrm{WGA}^{b}$ & Potato $^{e}$ & $\mathrm{BS} \mathrm{II}^{d}$ & Tomato ${ }^{e}$ \\
\hline D-Glucosamine & 0.009 & $<0.00003$ & & & \\
\hline$N$-Acetyl-D-glucosamine & 0.009 & 0.0003 & $<0.0003$ & 0.36 & $<0.008$ \\
\hline D-Mannosamine & 0.009 & & & & \\
\hline$N$-Acetyl-D-mannosamine & $<0.004$ & & & 00004 & $<0.008$ \\
\hline D-Galactosamine & $<0.003$ & & & & \\
\hline $\mathrm{N}$-Acetyl-D-galactosamine & $<0.004$ & & & $<0.0001$ & \\
\hline$N, N^{\prime}$-Diacetylchitobiose & 0.34 & 0.04 & 0.50 & 1.38 & 0.50 \\
\hline$N, N^{\prime}, N^{\prime \prime}$-Triacetylchitotriose ${ }^{f}$ & 1.00 & 1.00 & 1.00 & 1.00 & 1.00 \\
\hline$N, N^{\prime}, N^{\prime \prime}, N^{\prime \prime \prime}-$ Tetraacetylchitotetraose & 1.32 & 1.23 & 10.0 & & 8.00 \\
\hline $\begin{array}{l}p \text {-Nitrophenyl- } \alpha \text { - } N \text {-acetyl- } \\
\text { D-glucosaminide }\end{array}$ & $<0.012$ & & & 1.24 & \\
\hline $\begin{array}{l}p \text {-Nitrophenyl } \beta-\beta-N \text {-acetyl- } \\
\text { D-glucosaminide }\end{array}$ & 0.41 & 0.0014 & & 0.21 & \\
\hline \multicolumn{6}{|c|}{ a Conidiobolus lamprauges agglutinin; data from Table III of this paper. } \\
\hline \multicolumn{6}{|c|}{$b$ Wheat germ agglutinin; data from ref. 30 . } \\
\hline \multicolumn{6}{|c|}{ - Potato lectin; data from ref. 31} \\
\hline \multicolumn{6}{|c|}{ Bandeiraea simplicifolia II lectin; data from ref. 33 . } \\
\hline \multirow{2}{*}{\multicolumn{6}{|c|}{ e Tomato lectin; data from ref. 32}} \\
\hline & & & & & \\
\hline
\end{tabular}

the enzyme by FE may be due to a difference in the receptor-binding abilities or specificities of the agglutinin and enzyme. As the separation could be performed at $4^{\circ} \mathrm{C}$ when the $\beta-N$ acetylglucosaminidase was inactive, it was clear that the scarce adsorption of enzyme onto FE was not derived from the cleavage of $\beta-N$ acetylglucosaminidase bonds of receptors on FE by the enzyme.

Aggregation of hemagglutinin and successive reduction of hemagglutinating activity are the biggest unsolved problems for hemagglutinin purification. Also in the case of $\mathbf{L}$-fucosespecific hemagglutinin from Streptomyces sp., self-aggregation occurred when it was electrophoresed in the absence of SDS. ${ }^{12)}$ The polyacrylamide gel electrophoresis without SDS and the ultrafiltration indicated that the present hemagglutinin formed large aggregates. Until now, the native molecular weight has not been known. When the aggregates are turned to be re-native, a much higher value in specific activity of the hemagglutinin may be obtained.

In the SDS electrophoresis experiments, the hemagglutinin gave a band containing a small amount of sugar, with a molecular weight of $c a$. 86,000 daltons. The role of this sugar in the hemagglutinin molecule has not been clarified, but the unusual variation in molecular weight values corresponding to gel concentrations in SDS electrophoresis (Figs. 3 and 4) seem to indicate that the sugar was not a mere contaminant, but a constituent of glycoprotein. ${ }^{29)}$ It has not been clear whether the minor component in SDS electrophoresis is the isomer or derivative of the major component, and whether sugar is present in the minor component.

$N$-Acetyl-D-glucosamine-binding hemagglutinins are widely distributed in plants. ${ }^{2)}$ According to the hemagglutination inhibition tests, the $C$. lamprauges agglutinin was distingushed from known plant hemagglutinins (Table V) in specificity for $N$-acetyl-D-glucosamine oligomers; it differed from wheat germ agglutinin, ${ }^{30)}$ in response to D-glucosamine and $N, N^{\prime}$-diacetylchitobiose, from potato lectin ${ }^{31}$ and tomato lectin ${ }^{32)}$ to $N$-acetyl-D-glucosamine and $N, N^{\prime}, N^{\prime \prime}, N^{\prime \prime \prime}$-tetraacetylchitotetraose, and from Bandeiraea simplicifolia II lectin ${ }^{33}$ to $N$-acetyl-D-glucosamine. The agglutinin also differed from Cytisus type lectins, because it was resistant to cellobiose (Table IV), to which. Cytisus sessifolius ${ }^{25)}$ and Ulex europeus $\mathrm{II}^{26)}$ lectins are susceptible. C. lamprauges agglutinin was also distinguished from $B$. simplicifolia II lectin by the specificity for $p$-nitro- 
phenyl $\alpha$ - and $\beta$ - $N$-acetyl-D-glucosaminides. The lectin was efficently inhibited by $\alpha-N$ acetyl-D-glucosaminides, ${ }^{33)}$ while the $C$. lamprauges agglutinin was inhibited strongly only by $\beta$-anomers. These differences would be useful for the elucidation of the structure of sugar chains of glycoconjugates.

C. lamprauges hemagglutinin was strongly inhibited by $N$-acetyl chitobi, tri, and tetraose, moderately inhibited by phenyl and $p$-nitrophenyl $\beta$ - $N$-acetyl-D-glucosaminides, and weakly inhibited by D-glucosamine and $N$ acetyl-D-glucosamine (Table IV). Optimal ranges of pH (Fig. 5) and temperature (Fig. 6) for hemagglutinin action were far wider than those of $\beta$ - $N$-acetylglucosaminidase. Furthermore it is known that various $\beta-N$-acetylglucosaminidases hydrolyzed $p$-nitrophenyl- $\beta$ $N$-acetyl-D-glucosaminide faster than $N$-acetyl chito-olgomers. $^{34,35)}$ These facts mean that $\mathrm{N}$-acetyl chito-oligomers were superior as affinity adsorbents of the hemagglutinin, and the separation process should be performed at the certain $\mathrm{pH}$ and temperature ranges. Affinity chromatographies using various derivatives of $N$-acetyl-D-glucosamine, however, have not succeeded in separating the present aglutinin from coexisting $\beta-N$-acetylglucosaminidase.

Detailed properties of the hemagglutinin and $\beta$ - $N$-acetylglucosaminidase of $C$. lamprauges will be described elsewhere.

Acknowledgments. This work was supported in part by a Grant-in-Aid for Scientific Research from the Ministry of Education, Science and Culture of Japan (No. 347101), and a grant from Kaiun Mishima Memorial Foundation, Tokyo (1979).

\section{REFERENCES}

1) H. Lis and N. Sharon, Ann. Rev. Biochem., 42, 541 (1973).

2) I. J. Goldstein and C. E. Hayes, Adv. Carbohydr. Chem. Biochem., 35, 127 (1978).

3) J. C. Aub, C. Tieslau and A. Lankester, Proc. Natl. Acad. Sci. U.S.A., 50, 613 (1963).

4) M. M. Burger and A. R. Goldberg, Proc. Natl. Acad. Sci. U.S.A., 57, 359 (1967).

5) M. M. Burger, Proc. Natl. Acad. Sci. U.S.A., 63, 994 (1969).
6) R. Bloch and M. M. Burger, Biochem. Biophys. Res. Commun., 58, 13 (1974).

7) R. Lotan, N. Sharon and D. Mirelman, Eur. J. Biochem., 55, 257 (1975).

8) D. Mirelman, E. Galun, N. Sharon and R. Lotan, Nature, 256, 414 (1975).

9) Y. Fujita, K. Oishi and K. Aida, J. Biochem. (Tokyo), 76, 1347 (1974).

10) Y. Fujita, K. Oishi, K. Suzuki and K. Imahori, Biochemistry (U. S. A.), 14, 4465 (1975).

11) K. Oishi, S. Yokoshima, T. Tomiyama and K. Aida, Appl. Environ. Microbiol., 38, 167 (1979).

12) T. Kameyama, K. Oishi and K. Aida, Biochim. Biophys. Acta, 581, 407 (1979).

13) A. Takenaka, K. Oishi and K. Aida, J. Gen. Appl. Microbiol., 25, 397 (1979).

14) F. Ishikawa, K. Oishi and K. Aida, Appl. Environ. Microbiol., 37, 1110 (1979).

15) J. A. Raply, Biochim. Biophys. Acta, 83, 245 (1965).

16) W. T. Butler, J. Immunol, 90, 663 (1963).

17) R. W. Reitherman, S. D. Rosen and S. H. Barondes, Nature, 248, 599 (1974).

18) R. A. Reisfeld, U. J. Lewis and D. E. Williams, Nature, 195, 281 (1962).

19) B. J. Davis, Ann. N. Y. Acad. Sci., 121, 404 (1964).

20) K. Weber and M. Osbern, J. Biol. Chem., 244, 4406 (1969).

21) M. M. Bradford, Anal. Biochem., 72, 248 (1976).

22) R. M. Zacharius, T. E. Zell, J. H. Morrison and J. J. Woodlock, Anal. Biochem., 30, 148 (1969).

23) I. Matsumoto and T. Osawa, Arch. Biochem. Biophys., 140, 484 (1970).

24) T. Osawa, Biochim. Biophys. Acta, 115, 507 (1966).

25) R. Senju and S. Okimasu, Nippon Nögeikagaku Kaishi, 23, 432 (1950).

26) R. Kornfeld and S. Kornfeld, Ann. Rev. Biochem., 45, 217 (1976).

27) T. P. Nowak and S. H. Barondes, Biochim. Biophys. Acta, 393, 115 (1975).

28) D. L. Simpson, S. D. Rosen and S. H. Barondes, Biochim. Biophys. Acta, 412, 109 (1975).

29) J. P. Segrest, R. L. Jackson, E. P. Andrews and V. T. Marchesi, Biochem. Biophys. Res. Commun., 44, 390 (1971).

30) I. J. Goldstein, S. Hammarström and G. Sundblad, Biochim. Biophys. Acta, 405, 53 (1975).

31) A. K. Allen and A. Neuberger, Biochem. J., 135 307 (1973).

32) P. N. S. Iyer, K. D. Wilkinson and I. J. Goldstein, Arch. Biochem. Biophys., 177, 330 (1976).

33) D. C. Kilpatrick, Biochem. J., 185, 269 (1980).

34) K. M. L. Agrawal and O. P. Bahl, "Methods in Enzymology," Vol. 28, ed. by V. Ginsburg, Academic Press Inc., New York, N. Y., 1972, p. 720.

35) A. L. Tarentino and F. Maley, "Methods in Enzymology," Vol. 28, 1972, p. 772. 